\title{
Allanamiento de domicilio y tutela efectiva en el tráfico ilícito de drogas, Chachapoyas, 2016-2017
}

\section{Seizure of domicile and effective guardianship in illicit drug trafficking, Chachapoyas, 2016-2017}

Ángel Vásquez Valle

\section{RESUMEN}

El objetivo fue determinar si la inobservancia de presupuestos legales en el allanamiento domiciliario repercute en la tutela de los investigados ante la fiscalía provincial en delitos de tráfico ilícito de drogas, Chachapoyas, Perú, 2016-2017. La investigación aplico el método científico, fue cuantitativa y descriptiva, para recopilación de datos se utilizó el método dogmático, fichaje y guía documental, la población fue 164 carpetas fiscales, la muestra de 94 y el muestreo fue no probabilístico. En resultados, la incidencia del allanamiento domiciliario por tráfico de drogas en Chachapoyas, fue de 9 casos y no se aplicó los presupuestos legales en un $62.50 \%$ afectando la tutela de los investigados. En conclusión, la inobservancia de los presupuestos legales del allanamiento domiciliario repercute negativamente en la tutela de los investigados en la fiscalía provincial en delitos de tráfico de drogas, al no aplicar los principios de legalidad, proporcionalidad y razonabilidad.

Palabras clave: Allanamiento, domicilio, tutela, tráfico y drogas

\begin{abstract}
The objective was to determine if the non-observance of legal assumptions in the house raid affects the protection of those investigated before the provincial prosecutor's office in illicit drug trafficking crimes, Chachapoyas, Peru, 2016-2017. The research applied the scientific method, it was quantitative and descriptive, for data collection the dogmatic method, recording and documentary guide was used, the population was 164 fiscal folders, the sample of 94 and the sampling was non-probabilistic. In results, the incidence of house searches for drug trafficking Chachapoyas was 9 cases and the legal assumptions were not applied in $62.50 \%$, affecting the protection of those investigated. In conclusion, the non-observance of the legal assumptions of the house raid has a negative impact on the protection of those investigated in the provincial prosecutor's office in drug trafficking crimes, by not applying the principles of legality, proportionality and reasonableness.
\end{abstract}

Keywords: Trespassing, domicile, guardianship, trafficking and drugs 


\section{INTRODUCCIÓN}

En el proceso penal, la investigación preparatoria comprende diligencias orientadas a la búsqueda y adquisición de fuentes de investigación, que afectan derechos fundamentales de la persona, estas diligencias, según Velasco (1996), son actos procesales con los cuales se interfiere en el derecho fundamental de una persona como inculpado o tercero, contra su voluntad, por causa de la persecución penal. Para estas diligencias el Código Procesal Penal establece presupuestos legales que son de plena observancia prescrito en los artículos $202^{\circ}$ al $204^{\circ}$, contrario sensu, su inobservancia legal acarrearía que se considere como una prueba prohibida o ilícita proscrita en virtud de lo establecido en el artículo VII del Título preliminar y 159 del acotado cuerpo legal. Estos presupuestos son el principio de legalidad, como límite a la restricción de derechos en la búsqueda de pruebas, establecido en el artículo $202^{\circ}$ del Código Procesal Penal, y que constituye la delimitación legal de las atribuciones de las instituciones u organismos públicos encargados de la persecución penal, Maier (2003), señala que el Estado precisa de autorización expresa de la ley para que la actividad de sus órganos pueda considerarse legítima; el principio de proporcionalidad, por la cual la limitación de derechos exige circunstancias fácticas que respalden su viabilidad, Aranguena (1991) resalta la armonía que debe existir entre la intensidad de la afectación del derecho con la gravedad del hecho a investigar; el principio de razonabilidad y sospecha, que se sustentan en el ocultamiento del imputado y que se encuentren bienes delictivos o relevantes para la investigación; el principio de necesidad, ello implica que la medida sea estrictamente indispensable para conseguir los medios de prueba y, no exista una medida menos gravosa para ese mismo fin.

En la práctica judicial, se observó in situ, que, en el Distrito Fiscal de Amazonas, sede de Chachapoyas, la medida de restricción de allanamiento (artículo $214^{\circ}$ del Código Procesal Penal) solicitada por el Fiscal Provincial de la Fiscalía Especializado en Delitos de Tráfico Ilícito de Drogas no cumplen con la observancia de los principios de legalidad procesal, razonabilidad y proporcionalidad, Velasco (1996), acota que debe ser autorizada por el Juez mediante resolución previa, en función a indicios o pruebas que el Ministerio Público proporcione para justificar la medida, excepcionalmente, la Policía o el fiscal podrán ejecutar la medida solicitando luego la confirmación al Juez; aunque se advierte que en muchos casos la solicitud no se ampara en motivos razonables, no se especifica en forma detallada los ambientes a ser registrados, la finalidad especifica del allanamiento, las diligencias a practicar, etc.; la cual queda consumada a decir de Vásquez (2010), en el momento en el que ésta se materializa, es decir cuando la restricción del derecho fundamental se hace efectiva. Esta realidad vulnera el derecho a la tutela jurisdiccional efectiva prescrita en el artículo 139.3 de la Constitución al no respetarse sus derechos como el no ser sometido a procedimientos distintos de los previstos por la ley, obtención de resolución debidamente motivada y la observancia del principio de legalidad procesal.

Se planteó como problema: ¿De qué manera la inobservancia de los presupuestos legales en la medida de allanamiento domiciliario repercute en el derecho a la tutela jurisdiccional efectiva de los investigados ante la fiscalía provincial especializada en delitos de tráfico ilícito de drogas, Chachapoyas, 2016-2017?, cuyo objetivo general fue determinar de qué manera la inobservancia de los presupuestos legales en el allanamiento domiciliario repercute en el derecho a la tutela efectiva de los investigados ante la fiscalía provincial especializada en delitos de tráfico ilícito de drogas, Chachapoyas, 2016-2017. Objetivos específicos 1. Analizar allanamiento domiciliario en flagrancia delictiva en investigados ante la fiscalía provincial en delitos de tráfico ilícito de drogas, Chachapoyas, 2016-2017. 2. Analizar el allanamiento domiciliario con autorización del juez en los investigados ante la fiscalía provincial en delitos de tráfico ilícito de drogas, Chachapoyas, 2016-2017 y 3. Analizar los alcances del derecho de tutela judicial efectiva al momento de aplicar una medida restrictiva de allanamiento por tráfico ilícito de drogas.

La justificación de la investigación se enfocó en describir las deficiencias en la aplicación de los presupuestos legales en el allanamiento domiciliario al no observar los principios de legalidad, proporcionalidad y razonabilidad, poniendo énfasis en la actuación de los fiscales para que tengan mejor criterio al momento de solicitarlo, a los magistrados para que velen por que se cumplan, en aras de lograr una uniformidad de criterios en los magistrados y garantizar el derecho a la tutela jurisdiccional efectiva de los justiciables.

\section{MATERIAL Y MÉTODO}

Enfoque, nivel, tipo, diseño de investigación y lugar de estudio.

La investigación fue enfoque cuantitativo; nivel descriptivo; el tipo fue transversal y no participante; el diseño de investigación según Sandini (2003), fue "Diseño investigación-acción", cuyo propósito fundamental se centra en aportar información relevante y vacíos legales para poder proponer reformas en aras de una mejor justicia social. El lugar de estudio fue el Distrito Fiscal de AmazonasChachapoyas. La población fue de 164 carpetas fiscales, la muestra estuvo dada por 94 carpetas fiscales, tramitadas ante la Fiscalía Provincial Especializada en Delitos de Tráfico Ilícito de Drogas 
del Distrito Fiscal de Amazonas-Chachapoyas, donde fue solicitado o confirmado la medida de allanamiento en el periodo 2016-2017. El muestreo a decir de Hernández, et al (2006) fue no probabilístico en su modalidad de selección discrecional de una muestra a criterio de juicio del propio investigador, los criterios fueron que tengan la calidad de cosa juzgada, y que el A quo no tenga denuncia por corrupción.

La metodología se basó como refiere Hernández, et al (2006) en el metódico científico, observando la realidad de manera no participante, accediendo a información doctrinaria y legislativa, contrastándolo con las carpetas fiscales y cuestionario, para finalmente establecer las conclusiones, empleando como métodos propios del derecho, al método Dogmático que permitió comprender (tratados, manuales, revistas jurídicas, artículos científicos) las instituciones jurídicas sobre allanamiento de domicilio y tutela efectiva; y el método hermenéutico para entender y explicar (Constitución, tratados internacionales y código procesal penal) la ratio lege de las normas de la medida de allanamiento.

\section{Técnicas e instrumentos de recolección de datos}

Acorde con Sandini (2003) se aplicaron como técnicas el Fichaje textual y resumen, como instrumento el cuestionario validado por 3 metodólogos quienes verificaron la coherencia y pertinencia de los indicadores con las variables de estudio, arrojando un promedio de $94.80 \%$ por lo que reúne las condiciones metodológicas para ser aplicado. El cuestionario se aplico a 8 especialistas en tráfico ilícito de drogas, que cuentan con el grado académico, la especialidad y conocen la realidad judicial en Chachapoyas.

\section{Procedimiento para la recolección de datos}

1. Se elaboraron el cuestionario y el instrumento de validación, validado por 3 expertos 2 . Se recopiló información de bibliotecas públicas, así como de buscadores electrónicos Scielo y google académico. 3. Se recopilo la información relevante en las estadísticas judiciales y carpetas fiscales. 4. Se aplicó el cuestionario a abogados expertos en Tráfico de drogas para conocer su posición frente a la temática de investigación.

\section{Análisis de datos}

Los datos fueron procesados y tabulados en el programa de statistical Packaged for the social sciences para las ciencias sociales (SPSS). En lo referente a la presentación de los datos del instrumento, estos fueron plasmados en figuras estadísticas de barras.

\section{RESULTADOS}

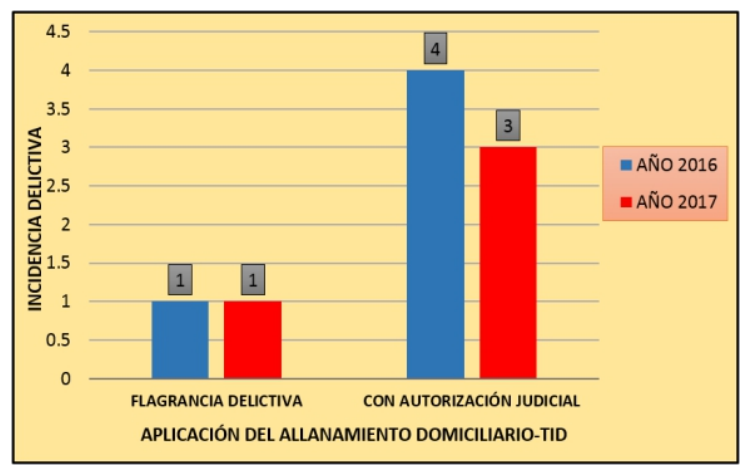

Figura 1. Incidencia delictiva en el allanamiento domiciliario según flagrancia delictiva y con autorización del juez, fiscalía provincial especializada en TID, Chachapoyas, 2016-2017.

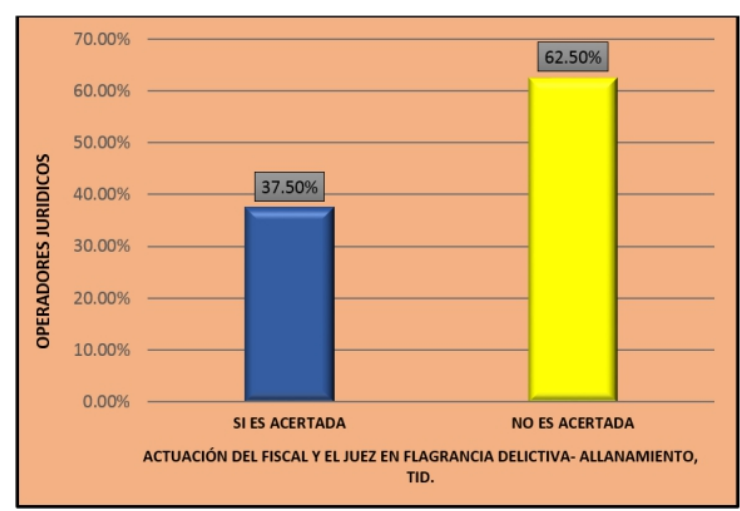

Figura 2. Los operadores jurídicos y la actuación del Fiscal y del Juez en el allanamiento en flagrancia delictiva por TID, según si es acertada o no es acertada.

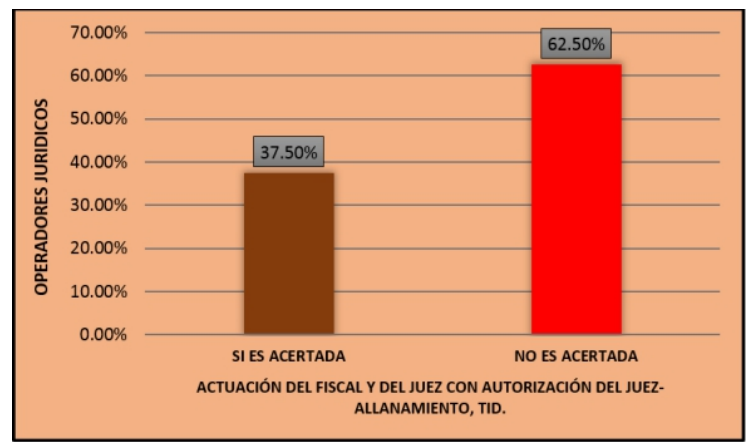

Figura 3. Los operadores jurídicos y la actuación del Fiscal y del Juez en el allanamiento con autorización del juez por TID, según si es acertada o no es acertada. 


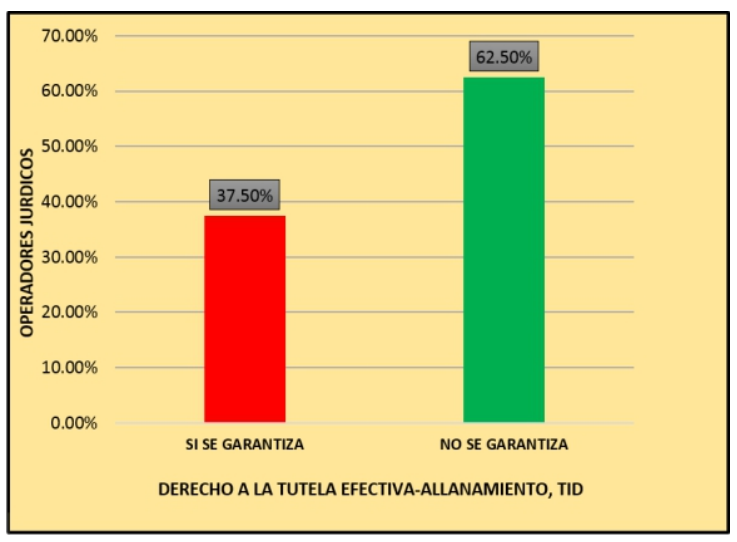

Figura 4. Los operadores jurídicos y el derecho de tutela judicial efectiva en el allanamiento por TID, según si se garantiza o no se garantiza.

\section{DISCUSIÓN}

Del análisis de la figura 1, referente a las carpetas fiscales sobre la medida de allanamiento domiciliario por el delito de tráfico ilícito de drogas en el distrito fiscal de Amazonas, sede de Chachapoyas, 20162017, se tiene en el año 2016 de 43 casos de allanamiento, se tiene 1 de flagrancia delictiva y 4 casos con autorización judicial, y en el 2017 de 51 casos de allanamiento, se tiene 1 de flagrancia delictiva y 3 casos con autorización judicial, en delitos de micro comercialización de droga y promoción al tráfico ilícito de drogas, en la flagrancia delictiva se cuestionan las actas por considerar que el fiscal no estuvo presente en las diligencias vulnerado el derecho de defensa, el requerimiento de confirmación judicial no cumple con las exigencias del artículo 203.2 del código Procesal Penal, y el A quo solo se guía de lo dicho por el fiscal sin corroborar la veracidad de lo descrito; estos resultados se contrastan con los datos de (Vicuña, L. 2012) quien refiere que el fiscal en su solicitud solo enumera y describe actos realizados, sin fundamentar las razonabilidad y el aporte en la investigación; en su aplicación con autorización del juez, el informe policial no sustenta debidamente la necesidad de sugerir la medida de allanamiento, el requerimiento del fiscal no está debidamente motivado y el A quo obvia el cumplimiento de los presupuestos emitiendo una resolución no motivada, estos resultados son contrastables con los estudios de (Landaverde, Et al 2002), quien refiere que en la práctica judicial existe una falta de fundamentación de las solicitudes y resoluciones judiciales que lo autorizan, las deficiencias administrativas de la Policía Nacional, la ausencia de los requisitos que debe reunir el consentimiento para ser válido; asimismo (Velasco, E. 1996), acota que el requerimiento del fiscal no es debidamente motivado y ello obedece a que el informe policial es muy superficial y no ofrece indicios razonables que requieran tal medida.

Del análisis de la figura 2, se tiene que el $37.50 \%$ de operadores jurídicos señalaron que es acertada y acorde a derecho la actuación del Fiscal y del Juez en la aplicación de la medida de allanamiento en flagrancia delictiva, aunque ellas signifiquen injerencias en la intimidad familiar o social así como pueden afectar otros derechos como la libertad individual, la inviolabilidad del domicilio, estos resultados son contrastables con los estudios de (Vicuña, 2012) quien señala que si la policía realiza allanamiento sin orden judicial y el Fiscal no solicita la confirmación judicial inmediata, las pruebas obtenidas se declaran ilícitas al momento de la audiencia de control de legalidad; el $62.50 \%$ indicaron que no es acertada y acorde a derecho la actuación del Fiscal y del Juez en la medida restrictiva de allanamiento en flagrancia delictiva, porque el personal policial no actúa de forma inmediata, no pone en conocimiento al Fiscal, y el fiscal no se apersona o llega cuando ya se ha realizado el allanamiento y registro domiciliario, esto se relaciona con los estudios de (Vásquez, 2010), quien refiere que los fiscales en la praxis judicial firman las actas de los cuales no han participado como defensores de la legalidad, y de otro lado el magistrado al emitir su resolución de confirmación judicial no cumple con las exigencias del artículo 203.2 del Código Procesal Penal.

En la figura 3, se observa que el $37.50 \%$ de operadores jurídicos señalaron que es acertada y acorde a derecho la actuación del Fiscal y el Juez en la aplicación de la medida con autorización del Juez, y el $62.50 \%$ indicaron que no es acertada y acorde a derecho la actuación del Fiscal y del Juez en la aplicación de la medida con autorización, porque ambos no cumplen con la observancia de los presupuestos legales y las formalidades de ley, en ese sentido (Landaverde, 2002), refiere que es un derecho fundamental exigir la debida motivación de la medida de allanamiento fáctica y jurídica fundándose en indicios verificables y con las garantías de ley. Mientras que el $37.50 \%$ expresa que la actuación del fiscal y del Juez es acorde a derecho porque cumplen con los presupuestos legales, las formalidades, el requerimiento y la resolución judicial autoritativa son motivados, estos resultados son contrastables con los estudios de (Sánchez, 2010), quien refiere que en la medida de allanamiento es procedente cuando resultan motivos fundados para considerar que en un domicilio, habitación, negocio, o cualquier otro lugar, se oculta el imputado u objetos relevantes para la investigación.

En la figura 4, se observa que el $37.50 \%$ señalaron que el A quo si cumple con garantizar el derecho de tutela efectiva, ya que cumplen con la jurisprudencia, cuando resaltan los requisitos de inmediatez temporal 
e inmediatez personal dentro de una percepción directa y efectiva del inmueble y de la necesidad urgente de la intervención policial como medio necesario de evitar la consumación del delito, estos resultados son contrastables con los estudios de (Calderón, 2006) que dice que el principio constitucional de la inviolabilidad del domicilio, no es absoluto, sino que se establecen en qué casos y con qué justificativos podrá procederse a su allanamiento; por su parte (Vicuña, 2012) acota que la administración de justicia debe cumplir con los principios de legalidad y proporcionalidad al caso sub litis para garantizar la tutela judicial efectiva; mientras que el $62.50 \%$ que el A quo no cumple con garantizar el derecho de tutela efectiva en los casos por tráfico de drogas porque desconocen y no aplican la jurisprudencia reiterada que existe sobre la medida de allanamiento; al respecto (Velasco, 1996) precisa que existen casos de requerimientos y confirmación judicial en donde se omite la jurisprudencia que salvaguarda los derechos de los investigados, así como legitimar un acto procesal sin que este haya contado con la presencia física del Fiscal; por su parte (Vicuña, 2012) agrega que la flagrancia no comprende información referencial o circunstancial para admitir la medida de allanamiento.

\section{CONCLUSIONES}

1. La incidencia delictiva del allanamiento domiciliario por tráfico ilícito de drogas arroja 2 casos en flagrancia delictiva y 7 casos con autorización del juez, se presenta en delitos de micro comercialización y promoción o favorecimiento al tráfico ilícito de drogas, se asocia a medidas de registro personal e incautación en donde su actuación no observo los principios de legalidad procesal, proporcionalidad y razonabilidad.

2. La actuación del Fiscal y del Juez en el allanamiento en flagrancia delictiva por TID, el $62.50 \%$ de los operadores jurídicos considera que no es acertada y acorde a derecho la actuación del Fiscal y del Juez de la investigación preparatoria, mientras que el $37.50 \%$ lo considera acertada porque cumplen con los presupuestos procesales que la ley establece en la medida de allanamiento.

3. La actuación del Fiscal y del Juez en el allanamiento con autorización del juez por TID, el $62.50 \%$ de los operadores jurídicos considera que no es acertada y acorde a derecho la actuación del Fiscal y del Juez por no estar motivada, mientras que el $37.50 \%$ lo considera acertada porque tanto el requerimiento como la resolución judicial son motivados fáctica y jurídicamente.
4.La aplicación de la medida de allanamiento por tráfico ilícito de drogas no garantiza en un $62.50 \%$ los alcances del derecho de tutela efectiva, debido a la inconstitucionalidad del allanamiento por no existir flagrancia delictiva y consentimiento del intervenido, y su inconstitucionalidad por indefensión material del imputado, mientras que el $37.50 \%$ es de la opinión que si aplica la ley y la jurisprudencia al caso concreto para garantizar su derecho.

\section{VI.- REFERENCIAS BIBLIOGRÁFICAS}

Aranguena, M. (1991). Teoría general sobre medidas cautelares. Barcelona: Bosch.

Calderón, A. (2006). Análisis Integral del Nuevo Código Procesal Penal. Lima: San Marcos.

Hernández, R. Fernández, C. y Baptista, P. (2006). Metodología de la investigación. México: Mc Graw hill.

Landaverde, S. (2002). Notas sobre el registro y allanamiento de morada como medida restrictiva a derechos fundamentales en el proceso penal salvadoreño.

http://www.cnj.gob.sv/web/documentos/publ icaciones/ventanajuridica.pdf

Maier, J. (2003). Derecho procesal penal. Buenos Aires: Del Puerto.

Sánchez, L. (2010). Las medidas restrictivas de derechos en el nuevo código procesal penal. $\mathrm{E}$ www.reddolac.org/profiles/blogs/medidasrestrictivas...

Sandini, M. (2003). Investigación cualitativa en educación: fundamentos y tradiciones. Madrid: Mc Graw hill.

Vásquez, M. (2010). La impugnación de las medidas restrictivas de derechos en el código procesal pen a $l$. E n : https://detorquemada.wordpress.com

Velasco, E. (1996). Medidas restrictivas de derechos fundamentales. Madrid: Consejo general del Poder Judicial.

Vicuña, L. (2012). El principio de legitimidad de la prueba y el requerimiento de confirmación judicial del allanamiento en los casos de flagrante delito y grave peligro de su 
perpetración.

En:www.derechoycambiosocial.com/allana

miento/casos_de_flagrancia.pdf 